\title{
TECTONIC SETTING AND SOURCE PARAMETERS \\ OF THE SEPTEMBER 19, 1985 MICHOACAN, MEXICO EARTHQUAKE
}

\author{
Holly Eissler, Luciana Astiz, and Hiroo Kanamori
}

Seismological Laboratory, California Institute of Technology, Pasadena, CA 91125

\begin{abstract}
Analysis of body waves and long-period surface waves from the September 1985 earthquake in coastal Michoacan, Mexico shows that the event was an interplate subduction event with a low dip angle fault plane $\left(\delta=9^{\circ}\right)$ striking parallel to the Mid-America trench $\left(\varphi=288^{\circ}\right)$ and a small component of left lateral motion $\left(\lambda=72^{\circ}\right)$ with a point source depth of $17 \mathrm{~km}$, and a seismic moment in excess of 1 $x 10^{28}$ dyn $\mathrm{cm}$. The earthquake was a multiple event, with a second source of identical moment, fault geometry, and depth occurring approximately $26 \mathrm{~s}$ after the first. Directivity in the body wave time function indicates that the second event occurred roughly $100 \mathrm{~km}$ to the southeast of the first. This suggests that the earthquake first broke the northern portion of the Michoacan gap, propagated with low moment release through the rupture zone of the 1981 Playa Azul earthquake, and then broke the remaining asperity in the southern section of the gap. The seismic moment determined from Rayleigh and Love waves is between $1.0-1.7 \times 10^{28}$ dyn $\mathrm{cm}\left(\mathrm{M}_{\mathrm{W}}=7.9-8.1\right)$, the largest moment determined to date for a Mexico subduction earthquake. Comparison of seismograms at Pasadena with records of other large Mexico events shows that the Michoacan earthquake is basically the same size as the 1932 Jalisco, Mexico earthquake, and clearly larger than other significant events in Mexico since 1932. The seismic moment and the time since the last large earthquake in Michoacan (in 1911) fit an empirical relation between moment and recurrence time found for the Guerrero-Oaxaca region of the subduction zone. The large aftershock on September $21\left(\mathrm{M}_{\mathrm{S}}=7.5\right)$ has the same geometry as the mainshock, a somewhat larger source depth $(22 \mathrm{~km})$, a simple time function, and a seismic moment between 2.9 $4.7 \times 10^{27}$ dyn $\mathrm{cm}\left(\mathrm{M}_{\mathrm{W}}=7.6-7.7\right)$.
\end{abstract}

\section{Introduction}

The September 19, 1985 earthquake in coastal Mexico was the most damaging event to date in that country; it cost over ten thousand lives, left hundreds of thousands homeless, and damaged over 800 buildings in Mexico City. Epicentral parameters from the National Earthquake Information Center (NEIC) in Golden, $\mathrm{CO}$ are $18.27^{\circ} \mathrm{N}, 102.31^{\circ} \mathrm{W}$, origin time $13 \mathrm{~h} 17 \mathrm{~m} 48.1 \mathrm{~s}$ UT, depth $33 \mathrm{~km}$ (fixed), and $\mathrm{M}_{\mathrm{S}}=8.1$. The event occurred along a part of the Cocos-North American plate boundary identified as the Michoacan seismic gap [Kelleher et al., 1973]. The gap had been quiescent since at least 1911 , when a damaging magnitude $73 / 4$ event occurred there [Gutenberg and Richter, 1954].

Figure 1 shows the aftershock areas of all shallow thrust events in coastal Mexico since 1950 with $M \geqslant 7$. Segments of the plate interface immediately adjacent to the Michoacan gap have experienced recent events at short and regular intervals. To the northwest, the Colima area recently had events

Copyright 1986 by the American Geophysical Union.

Paper number 6L6080.

0094-8276/86/006L-6080\$03.00 in 1941 and 1973 (a 32 yr interval), and to the southeast, the Petatlán area in northern Guerrero had events in 1943 and 1979 (a 36 yr interval). An average recurrence interval for the plate boundary of $33 \pm 8$ yrs was found by McNally and Minster [1981], although different sub-segments have somewhat different intervals [Astiz and Kanamori, 1984]. South of the Petatlán zone in the middle of the coast, the area void of recent large earthquake activity is the Guerrero seismic gap. The distance from Mexico City to the Guerrero gap is shorter than to any other region along the Mid-America trench. The last major events located in the Guerrero gap were in $1899(\mathrm{M} \sim 8)$ and $1907(\mathrm{M} \sim 8)$ [Astiz and Kanamori, 1984].

The Acapulco earthquake $\left(M_{S}=7.5\right)$ occurred in southern Guerrero in 1957 and damaged hundreds of buildings in Mexico City; however the number of structures experiencing complete collapse was far less than for the September 1985 earthquake. South of Acapulco, the plate interface is fairly well filled in with recent large earthquakes. The largest earthquake prior to 1985 was located near coastal Jalisco in 1932 $\left(\mathrm{M}_{\mathrm{S}}=8.1\right)$, shown by the dashed region in Figure 1 .

In 1981, the Playa Azul earthquake $\left(\mathrm{M}_{\mathrm{W}}=7.3\right)$ occurred in the center of the Michoacan gap. The epicenter of the September 1985 earthquake was located in the northern segment of the Michoacan gap between the 1973 and 1981 aftershock zones. Figure 1 shows the locations of the one-month aftershocks (locations are preliminary from NEIC and are plotted only for events reporting $\geqslant 10$ arrival times). The aftershocks generally lie between the limits of the 1973 and 1979 aftershock zones, and there is some indication that there was less aftershock activity within the small zone that slipped in the Playa Azul earthquake. The largest aftershock $\left(\mathrm{M}_{\mathrm{S}}=7.5\right)$ occurred approximately 36 hours after the mainshock on September 21 in the southern part of the gap between the 1981 and 1979 aftershock zones. Activity appears to terminate at the northern boundary of the 1979 zone; however two fairly large late events occurred south of the 1979 zone, on September $28\left(m_{b}=5.0\right)$ and October 3 $\left(m_{b}=4.5\right)$, in the northernmost region of the Guerrero gap.

It had been suggested by Singh et al. [1980] that the $M=7$ $3 / 4$ event in 1911 , located in the Michoacan area by Gutenberg and Richter [1954], was actually about $200 \mathrm{~km}$ further northwest in Jalisco, and that the lack of other large earthquakes in the historical record in the Michoacan area could signify a "permanent" seismic gap. Coincident with the Michoacan gap, the Orozco fracture zone intersects the MidAmerica trench for about $150 \mathrm{~km}$. Previous to the September 1985 earthquake, the Michoacan area, with its seismic quiescence and subducting fracture zone, was similar to the southern Oaxaca area, where the Tehuantepec Ridge is subducting, and where there are no large earthquakes in the historic record. One possibility suggested to explain the seismic quiescence in these areas was that features such as the Orozco fracture zone and the Tehuantepec Ridge may be locally affecting the subduction process, such that the area is subducting aseismically, or more slowly than adjacent regions of the plate boundary [Singh et al,, 1980; McNally and Minster, 1981; LeFevre and McNally, 19851. Alterations of subduc- 


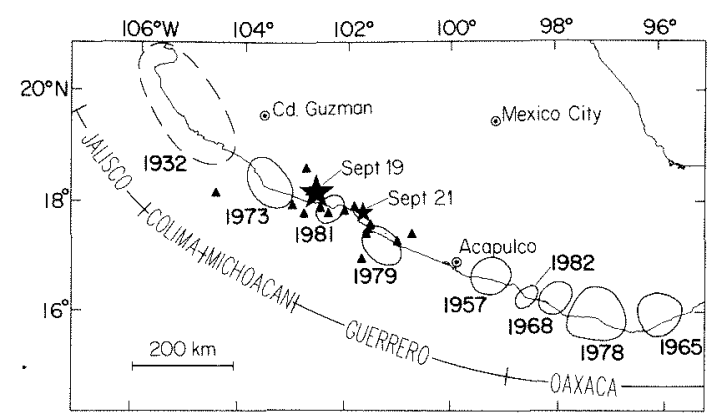

Fig. 1. Map of central Mexico showing the aftershock areas (ellipses) of subduction events since 1950 with $M>7$. The September 1985 earthquake is plotted as a filled star, and its $\mathrm{M}_{\mathrm{S}}=7.5$ aftershock as a smaller star. Other symbols are the one-month aftershocks, whose locations are preliminary from NEIC. The dashed region is the aftershock area of the $\mathrm{M}_{\mathrm{S}}=$ 8.1 Jalisco event [Singh et al., 1985]. References for other aftershock areas are in Astiz and Kanamori [1984].

tion characteristics are observed in other circum-Pacific regions where areas of topographically anomalous seafloor are subducting [Vogt et al., 1976].

The intensity pattern of the 1911 event was similar to the 1985 Michoacan event, suggesting a similar epicenter. The literature reports that the "center of disturbance" (e.g., deaths, damage to homes, and strong shaking) was near Ciudad Guzman in Jalisco, about $260 \mathrm{~km}$ from Gutenberg and Richter's epicenter [Branner, 1912; Figueroa, 1959]. The 1985 event also caused fatalities and structural collapse in Ciudad Guzman. Like the 1985 event, the 1911 event caused deaths in Mexico City; the reported intensity there was VIII, the largest of any earthquake during 1900-1959. For comparison, the intensity in Mexico City from the $\mathrm{M}_{\mathrm{S}} 8.11932$ Jalisco event was only V [Figueroa, 1959]. Examination of Gutenberg and Richter's epicenter determination for the 1911 earthquake reveals that data from Mexico (three S-P times and one direct $\mathrm{P}$ time) were included in their analysis and support a location offshore northern Michoacan.

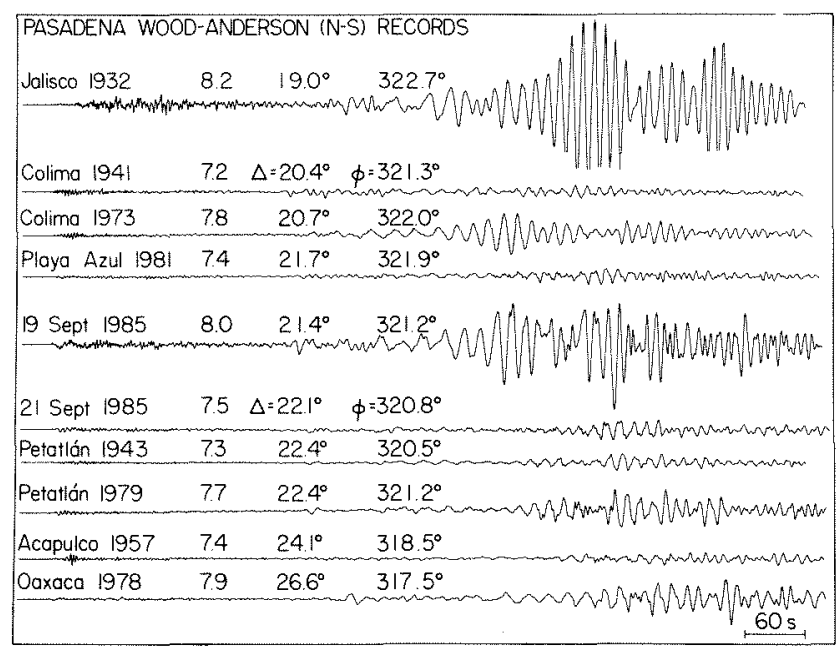

Fig. 2. N-S component records of large thrust events in Mexico from the Wood-Anderson intrument in Pasadena. Events are ordered geographically from northwest (top) to southeast (bottom). Amplitudes are indicative of magnitude since events have similar depths and mechanisms. The September 1985 earthquake is larger than all other events excluding the 1932 Jalisco earthquake. $M_{S}$ values determined from the surface wave amplitudes are shown.

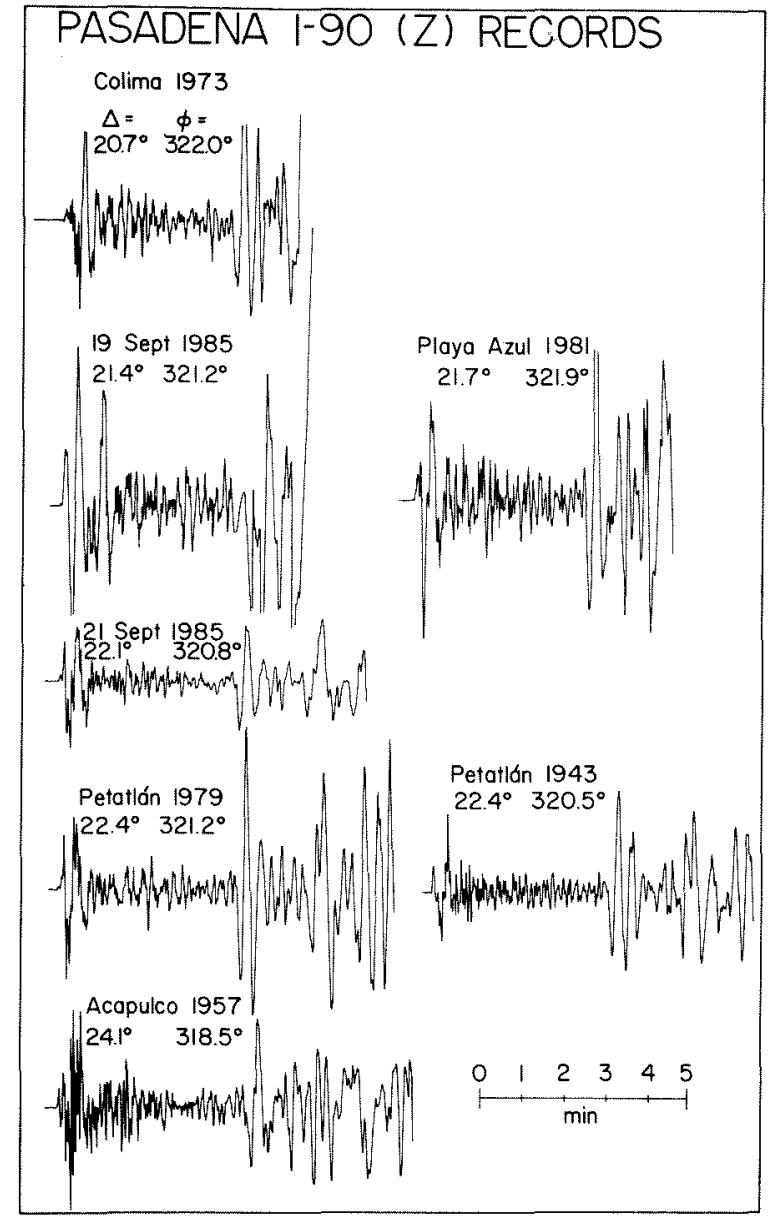

Fig. 3. Records of the same events on a broadband vertical intrument. Waveforms are remarkably similar between events, except for the September 19, 1985 Michoacan record, which shows a second arrival within $1 \mathrm{~min}$ of the $\mathrm{P}$ wave, indicative of source complexity.

\section{Pasadena Seismograms from Large Mexico Earthquakes}

Records from instruments at the Seismological Laboratory in Pasadena, CA from the largest subduction events in Mexico were gathered for comparison in different period bands. Figure 2 shows about 12 minutes of the north-south component of the horizontal Wood-Anderson instrument. Although surface wave amplitudes are affected by the source depth and mechanism, most of these events have similar depths $(16-20 \mathrm{~km}$ ) and mechanisms (reverse faulting on a low angle plane parallel to the trench) [Chael and Stewart, 1982; Singh et al., 1984]. Thus amplitude differences should be indicative of differences in magnitude. Figure 2 shows three basic sizes of events. The 1932 Jalisco earthquake has offscale surface waves, and the 1985 Michoacan earthquake surface waves are nearly as large. The Colima 1973, Petatlán 1979, and Oaxaca 1978 are comparatively sized events. The Colima 1941, Petatlán 1943, Playa Azul 1981, Michoacan September 1985 aftershock, and Acapulco 1957 earthquakes have the smallest amplitudes. The Acapulco earthquake is anomalous in having a large body wave pulse compared to its surface waves. $M_{S}$ values determined from the WoodAnderson records are shown in the Figure.

Figure 3 shows records from the broadband vertical Benioff instrument $\left(T_{p}=1 \mathrm{~s}, T_{g}=90 \mathrm{~s}\right)$. This instrument was not installed at the time of the 1932 earthquake. The records 
show the $\mathrm{P}$ wave, $\mathrm{S}$ arrival at approximately $4 \mathrm{~min}$, and beginning of the surface wave. The most remarkable feature is the similarity of the waveforms between events, indicating similar source parameters and time functions. The notable exception is the Michoacan mainshock, which shows a late arrival less than 1 min behind the characteristic $P$ waveform, indicative of a complex time function. The Acapulco earthquake has an unusual amount of high frequency, but the overall waveform has the same shape as the other events.

\section{Source Parameters from Body Wave Modeling}

$P$ waves from the earthquake recorded globally on longperiod vertical instruments can be modeled by a time function of 2 trapezoidal sources of equal duration and moment about $26 \mathrm{~s}$ apart at $17 \mathrm{~km}$ source depth and an overall thrust geometry on a low angle plane $\left(\delta=9^{\circ}, \varphi=288^{\circ}, \lambda=72^{\circ}\right)$. Figure 4 shows observed and calculated waveforms for 11 WWSSN stations and one GEOSCOPE station, as well as the focal mechanism and $P$ wave first motion data. The seismic moment from the body wave modeling is $8.3 \times 10^{27} \mathrm{dyn} \mathrm{cm}$. The slip direction of this mechanism is $37^{\circ}$, precisely the local direction of motion of the Cocos plate at the epicentral location calculated from its pole of rotation.

This source depth and mechanism are essentially the same as those of all other large Mexico interplate subduction events studied to date. However, the double source time function is unusual. Body wave modeling has shown that most large Mexico subduction events have simple time functions [Chael and Stewart, 1982]. For the few events that show a complex time function, the dominant moment release still occurs in one simple pulse [Astiz and Kanamori, 1984; Singh et al., 1984]. The exception is the 1932 Jalisco earthquake, which had a second event of equal size approximately $30 \mathrm{~s}$ after the first, much like the time function of the Michoacan earthquake [Singh et al., 1984]. Earthquakes with larger seismic moments such as in 1932 and 1985 tend to have larger rupture zones, increasing the chance of breaking through several asperities to create a multiple time function.

The time separation $t_{o}$ between the two sources was adjusted with azimuth for the best fit between observed and calculated waveforms. The longest time separation was $31 \mathrm{~s}$ for stations in northwest azimuths, and the shortest was $21 \mathrm{~s}$ for stations in southeast azimuths. Stations with northeast azimuths and southwest azimuths had intermediate separations of $26 \mathrm{~s}$ and $29 \mathrm{~s}$ respectively. This systematic pattern indicates that the second source was located southeast of the

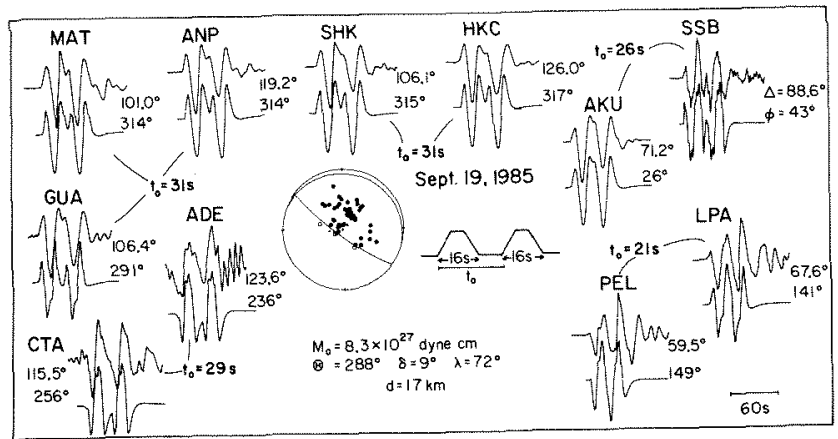

Fig. 4. Observed (above) and calculated waveforms of $P$ waves from long-period WWSSN and one GEOSCOPE stations at teleseismic distances. The observed waveforms are matched with the focal mechanism shown and a point source depth of $17 \mathrm{~km}$, and a two source time function whose time separation $t_{o}$ varies systematically with azimuth, indicating source directivity.
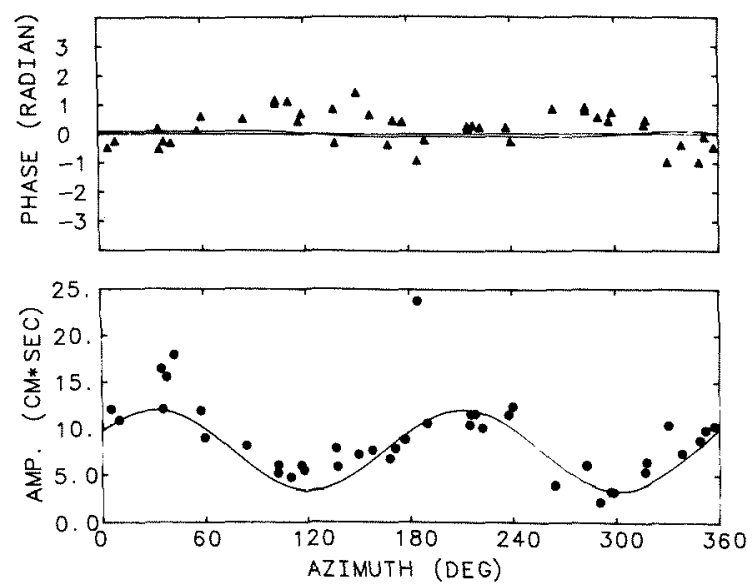

Fig. 5. Observed phase (triangles) and amplitude (circles) spectral values vs. azimuth of Rayleigh wave data compared with the theoretical pattern for the best solution. Spectral values are at $256 \mathrm{~s}$ period.

first. If a fault strike parallel to the trench is assumed, the observed variation in $t_{0}$ gives a spatial separation of about $100 \mathrm{~km}$. The scenario is that the earthquake first broke the north part of the Michoacan gap, propagated to the southeast with low moment release through the 1981 rupture zone, and then broke the southern segment of the gap.

$P$ wave modeling of the aftershock shows a mechanism identical to the mainshock, with a slightly greater source depth $(22 \mathrm{~km})$. The aftershock time function is a single trapezoid with duration of $13 \mathrm{~s}$. The seismic moment from the body waves is $1.2 \times 10^{27} \mathrm{dyn} \mathrm{cm}$.

\section{Moment Determination from Long-Period Surface Waves}

The seismic moment and fault geometry of the earthquake were resolved from amplitude and phase spectral data of multiple Rayleigh and Love wave passages at $256 \mathrm{~s}$, generally following Kanamori and Given [1981]. The moment tensor source representation was not used due to the complication of some moment tensor components being unconstrained at shallow source depths. Instead, the steeply dipping auxiliary plane was held fixed at the orientation from the first motion solution $\left(\delta_{\mathrm{a}}=81^{\circ}, \varphi_{\mathrm{a}}=127^{\circ}\right)$ and the surface wave data was inverted for the best-fitting values of seismic moment $M_{o}$ and slip angle $\lambda_{\mathrm{a}}$, using excitation functions for a source depth of $16 \mathrm{~km}$. A data set of 42 Rayleigh wave phases $\left(R_{2}\right.$ through $R_{4}$, with 26 phases from the IDA network and 16 phases from GDSN) with a good azimuthal coverage returned a solution with $\lambda_{\mathrm{a}}=91.9^{\circ}$ and $\mathrm{M}_{\mathrm{o}}=1.7 \times 10^{28} \mathrm{dyn} \mathrm{cm}$. The parameters for the fault plane are then $\delta=9.2^{\circ}, \varphi=295^{\circ}$, and $\lambda=78^{\circ}$. Figure 5 shows the fit between the observed and calculated Rayleigh wave radiation pattern. When 10 Love wave phases were included, the solution was virtually identical $\left(\lambda_{\mathrm{a}}=92.2^{\circ}, \mathrm{M}_{\mathrm{o}}=1.6 \times 10^{28} \mathrm{dyn} \mathrm{cm}\right)$. The source process time $\tau$ was about $100 \mathrm{~s}$. Inversion of 26 Rayleigh wave phases from the IDA network for the September 21 aftershock, again with the steep plane fixed, returned the same geometry $\left(\lambda_{\mathrm{a}}=92.9^{\circ}\right.$, or $\delta=9.5^{\circ}, \varphi=289^{\circ}, \lambda=73^{\circ}$ for the fault plane), a seismic moment of $4.7 \times 10^{27} \mathrm{dyn} \mathrm{cm}$, and $\tau$ about $60 \mathrm{~s}$.

The constraint on the fixed auxiliary plane forces the inversion to return a very shallow dip $\left(9^{\circ}\right)$ for the fault plane. Although this agrees with the dip determined from body wave modeling, the fault plane representative of the overall moment release may have a somewhat greater dip. For shallow events, the seismic moment from the surface wave inver- 
sion depends on the dip angle assumed as $\mathrm{M}_{\mathrm{O}_{i 1}} / \mathrm{M}_{\mathrm{O}_{(2)}}=\sin 2 \delta_{(2)} / \sin 2 \delta_{(1)}$ [Kanamori and Given, 1982]. Thus for a dip of $15^{\circ}$ instead of $9^{\circ}$ the moment is smaller by about a factor of 2 . In our judgement $15^{\circ}$ is a maximum value for dip, and the moment range for the mainshock is $1.1-1.7 \times 10^{28}$ dyn $\mathrm{cm}\left(\mathrm{M}_{\mathrm{W}}=7.9-8.1\right)$. For the aftershock, the moment range is $2.9-4.7 \times 10^{27} \mathrm{dyn} \mathrm{cm}$, or $\mathrm{M}_{\mathrm{W}}=7.6-$ 7.7 .

\section{Relation Between Recurrence Time and Seismic Moment}

Astiz and Kanamori [1984] noted an empirical relation between the average seismic moment per region and the average recurrence time per region for large earthquakes in the Mexico subduction zone:

$$
\log T=1 / 3 \log M_{o}-7.5,
$$

where $T$ is in years and $M_{0}$ in dyn $\mathrm{cm}$. Using 1911 as the last event date in the Michoacan gap, their relation predicts a seismic moment of $1.3 \times 10^{28}$ dyn $\mathrm{cm}$ for an event in 1985 , which is within the moment range found for the Michoacan earthquake. Astiz and Kanamori based their relation on activity in the Guerrero-Oaxaca region of the subduction zone, and noted that it did not hold north of the Michoacan gap; we can now tentatively extend it into the Michoacan area. Equation (1) implies that an impending event in the Guerrero gap would have a large seismic moment $\left(\approx 10^{28}\right.$ dyn $\mathrm{cm}$ ). For the purposes of the $T-M_{0}$ relation, one single $M_{W}=8.0$ event would be equivalent to two $M_{W}=7.8$ events occurring, say, months apart; however, these two cases may have very different outcomes in terms of damage.

\section{Conclusions}

The seismic moment of the 1985 Michoacan earthquake is between $1.1-1.7 \times 10^{28}$ dyn $\mathrm{cm}\left(\mathrm{M}_{\mathrm{W}}=7.9-8.1\right)$. Thus the event is comparable with the largest previous event in the Mexico historic record, the $1932 \mathrm{M}_{\mathrm{S}} 8.1$ Jalisco earthquake.

The seismic moment of the aftershock is $2.9-4.7 \times 10^{27}$ dyn $\mathrm{cm}\left(\mathrm{M}_{\mathrm{W}}=7.6-7.7\right)$.

Source parameters from body wave modeling are fault dip, $9^{\circ}$; fault strike, $288^{\circ}$; slip angle, $72^{\circ}$; and source depth, 17 $\mathrm{km}$, essentially the same mechanism and depth as other interplate subduction events in Mexico.

The earthquake had a complex time function consisting of two equal pulses with the second source approximately $26 \mathrm{~s}$ after the first. The second source was resolved to be about $100 \mathrm{~km}$ southeast of the first from observed directivity in the body waves. The two-source time function plus the aftershock distribution imply that the earthquake broke the two remaining asperities in the Michoacan gap to the north and south of the 1981 Playa Azul rupture zone.

The longer source duration may have been a factor in the severe damage in Mexico City. Residents of Mexico City told us that while they had felt comparatively strong earthquakes in the past 40 years, the Michoacan event was notable in its unusual length of shaking.

The seismic moment of the event is consistent with an empirical relation between moment and recurrence time for the Mexico subduction zone. The relation implies that an earthquake in the Guerrero gap could have a similar seismic moment $\left(\sim 10^{28} \mathrm{dyn} \mathrm{cm}\right)$. Alternatively, the Guerrero gap could break in a series of smaller events within a few years of each other and still be in accord with the empirical relation.
Acknowledgements. We thank personnel at many WWSSN stations, Project GEOSCOPE of Institut de Physique du Globe in Paris, Project IDA at Institute for Geophysics and Planetary Physics at the University of California, San Diego, the Center for Seismic Studies in Washington, D.C., and the U.S. Geological Survey, for sharing their data in advance of normal distribution. We enjoyed discussions. with colleagues at the special session on the Michoacan earthquake at the 1985 Fall AGU meeting. This research was supported by USGS Grant 14-08-0001-G1170. Contribution No. 4314, Division of Geological and Planetary Sciences, California Institute of Technology, Pasadena, CA 91125.

\section{References}

Astiz, L., and H. Kanamori, An earthquake doublet in Ometepec, Guerrero, Mexico, Phys. Earth Planet. Int., 34, 24-45, 1984.

Branner, J., in Reviews, Bull. Seismol. Soc. Am., 3, p. 12, 1912.

Chael, E. P., and G. S. Stewart, Recent large earthquakes along the Middle American Trench and their implications for the subduction process, J. Geophys. Res., 87, $329-338,1982$.

Figueroa, J. A., New seismic chart of Mexico, Anales del Instituto de Geofísica, Universidad Nacional Autonoma de México, 5, 45-162, 1959.

Gutenberg, B., and C. F. Richter, Seismicity of the Earth and Associated Phenomena, 135 pp., Princeton University Press, Princeton, NJ, 1954.

Kanamori, H., and J. W. Given, Use of long-period surface waves for rapid determination of earthquake source parameters, Phys. Earth Planet. Inter., 27, 8-31, 1981.

Kanamori, H., and J. W. Given, Use of long-period surface waves for rapid determination of earthquake source parameters, 2. Preliminary determination of source mechanisms of large earthquakes $\left(\mathrm{M}_{\mathrm{S}} \geqslant 6.5\right)$ in 1980 , Phys. Earth Planet. Inter., 30, 260-268, 1982.

Kelleher, J., L. Sykes, and J. Oliver, Possible criteria for predicting earthquake locations and their application to major plate boundaries of the Pacific and the Caribbean, J. Geophys. Res., 78, 2547-2585, 1973.

LeFevre, L. V., and K. C. McNally, Stress distribution and subduction of aseismic ridges in the Middle America subduction zone, J, Geophys. Res., 90, 4495-4510, 1985.

McNally, K. C., and J. B. Minster, Nonuniform seismic slip rates along the Middle America Trench, J. Geophys. Res., 86, 4949-4959, 1981.

Singh, S. K., L. Ponce, and S. P. Nishenko, The great Jalisco, Mexico earthquakes of 1932: Subduction of the Rivera plate, Bull. Seismol. Soc. Amer., 5, 1301-1314, 1985.

Singh, S. K., J. Yamamoto, J. Haskov, M. Guzmán, D. Novelo, and R. Castro, Seismic gap of Michoacan, Mexico, Geophys. Res. Lett., 7, 69-72, 1980.

Singh, S. K., T. Dominguez, R. Castro, and M. Rodriguez, P waveform of large, shallow earthquakes along the Mexican subduction zone, Bull. Seismol. Soc. Amer., 74, 2135-2156, 1984.

Vogt, P. R., A. Lowrie, D. Bracey, and R. Hey, Subduction of aseismic oceanic ridges: Effects on shape, seismicity, and other characteristics of consuming plate boundaries, Geol. Soc. Amer. Spec. Pap., 172, 1976.

(Received February 21, 1986 Accepted March 28, 1986) 